\title{
Porencephalic Cyst in an Adult - A Rare Pathology
}

\author{
Shreya Tapadia ${ }^{1}$, Suresh Vasant Phatak ${ }^{2}$, Harshith Gowda K.B ${ }^{3}$, Asish Pavanan ${ }^{4}$ \\ 1,2,3,4 Department of Radio Diagnosis, Jawaharlal Nehru Medical College (JNMC), \\ Sawangi (Meghe), Wardha, Maharashtra, India.
}

Porencephalic cyst is a rare entity in adults with limited cases reported so far. It is usually congenital and seen in neonates. Here, we report a 25 -year-old male who presented with post-ictal confusion following an episode of sudden onset of generalised tonic clonic seizure. He was diagnosed to have large cerebrospinal fluid (CSF) density cystic lesion in the right parieto-occipital region communicating with occipital horn on right side side of porencephaly.

Porencephaly is an uncommon congenital disorder that occurs due to cystic degeneration and encephalomalacia leading to porencephalic cyst formation. ${ }^{1}$ They are considered to occur most commonly from focal encephalomalacia due to a localised cerebral insult during early gestation, ${ }^{2}$ while the other aetiologies include trauma, infection, antenatal intraparenchymal haemorrhage and perinatal cerebral ischemia. $^{3}$

If the insult occurs in late third trimester it can lead to gliosis. Porencephalic cysts are typically lined by white matter of brain parenchyma. ${ }^{2}$ They differ widely in their location and size while the clinical manifestations and presentations range from being asymptomatic to extremely impaired mental function. Generally, the signs and symptoms of porencephaly become apparent in the first year of life. The earliest manifestation being spasticity and seizures.

As the age increases there is a delay in development of milestones presenting as language impairment, disability in intellect and motor deficits. Clinically head circumference measurement varies from being normal or small to an enlarged head in cases of synechiae formation that creates a one-way valve effect leading to progressive enlargement of the cyst and expansion of skull or there may be hydrocephalus. ${ }^{4}$

Radiologically the diagnosis depends on demonstrating a well-defined CSF-filled space occupying lesion lined by white matter and communicating with ventricles on computed tomography (CT) scan or magnetic resonance imaging (MRI) of brain. The prognosis of porencephaly depends on the location and extent of the cyst. ${ }^{5}$ If the cyst is very large it can cause mass effect in the form of scalloping of adjacent bone, buckling of brain parenchyma, midline shift to contra lateral side and hydrocephalus. On MRI, brain cyst appears well defined and lined by white matter with or without gliosis. Cerebrospinal fluid is the content which is shown as hypointense on T1 and hyperintense on $\mathrm{T} 2$.
Corresponding Author: Dr. Suresh V. Phatak,

Professor,

Department of Radio Diagnosis,

JNMC, Sawangi (Meghe),

Wardha - 442001,

Maharashtra, India.

E-mail: suresh_phatak@yahoo.com

DOI: $10.14260 / j e m d s / 2021 / 198$

How to Cite This Article:

Tapadia S, Phatak SV, Gowda HKB, et al. Porencephalic cyst in an adult - a rare pathology. J Evolution Med Dent Sci 2021; 10(12):918-919, DOI:

10.14260/jemds/2021/198

Submission 18-11-2020,

Peer Review 21-01-2021

Acceptance 02-02-2021,

Published 22-03-2021.

Copyright (c) 2021 Shreya Tapadia et al. This is an open access article distributed under Creative Commons Attribution License [Attribution 4.0 International (CC BY 4.0)] 
Fluid-attenuated inversion recovery (FLAIR) shows suppression of fluid signal intensity and diffusion-weighted imaging (DWI) with no restricted diffusion. ${ }^{6}$ The differential diagnosis for the porencephalic cyst includes ependymal cyst, schizencephaly and arachnoid cyst.

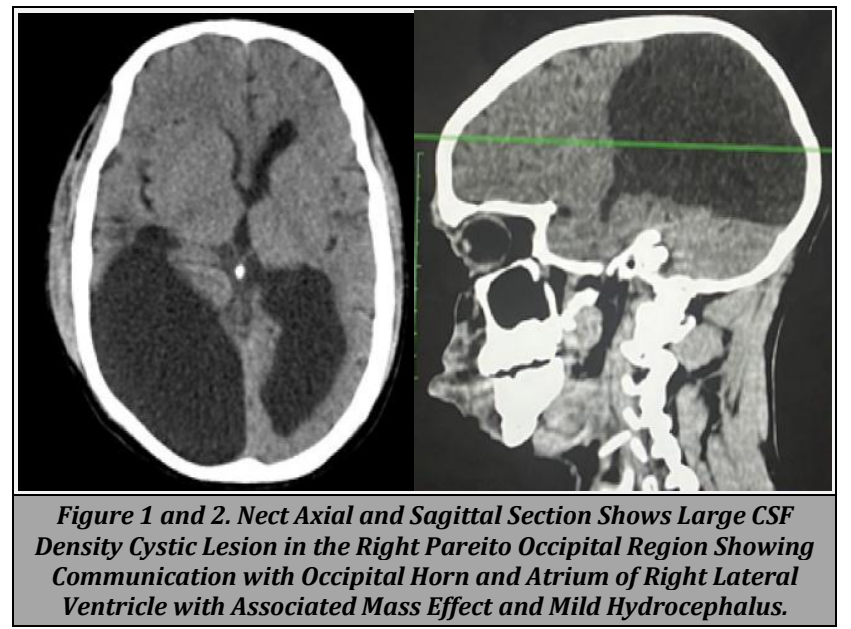

Financial or other competing interests: None.

Disclosure forms provided by the authors are available with the full text of this article at jemds.com.

\section{REFERENCES}

[1] Bianchi DW, Crombleholme TM, D'Alton ME. Fetology: diagnosis \& management of the fetal patient. New York, NY: McGraw-Hill Professional 2000.

[2] Roessmann U, Gambetti P. Pathological reaction of astrocytes in perinatal brain injury. Immunohistochemical Study. Acta Neuropathol 1986; 70(3-4):302-7.

[3] Grant EG, Kerner M, Schellinger D, et al. Evolution of porencephalic cysts from intraparenchymal hemorrhage in neonates: sonographic evidence. AJR Am J Roentgenol 1982; 138(3):467-70.

[4] Kaufman HH. Cerebrospinal fluid collections. $1^{\text {st }}$ edn. Thieme / American Association of Neurological Surgeons Publication 1997.

[5] Abrunhosa J, Gonçalves P, dos Santos JG, et al. Traumatic porencephalic cyst and cholesteatoma of the ear. J Laryngol Otol 2000; 114(11):864-6.

[6] Ramsey RG, Huckman MS. Computed tomography of porencephaly and other cerebrospinal fluid-containing lesions. Radiology 1977; 123(1):73-7. 